\title{
Medical versus surgical treatment for early pregnancy loss in infertile patients: Which approach facilitates more rapid return to subsequent treatment cycle?
}

\author{
Victoria Vallejo ${ }^{1}$, Hilde I. G. Cotton ${ }^{1}$, Joseph A. Lee ${ }^{1 *}$, Enrique Cervantes ${ }^{1}$, Benjamin Sandler ${ }^{1,2}$, \\ Alan B. Copperman ${ }^{1,2}$ \\ ${ }^{1}$ Reproductive Medicine Associates of New York, New York, USA \\ ${ }^{2}$ Reproductive Endocrinology, Mount Sinai School of Medicine, New York, USA \\ Email: ${ }^{*}$ jlee@,rmany.com
}

Received 7 September 2012; revised 6 October 2012; accepted 15 October 2012

\begin{abstract}
Patients and physicians confront a challenging dynamic when an early pregnancy loss (EPL) occurs after fertility treatment (FT). Our study focused on the time to resumption of FT in patients managed medically (Cytotec) compared to in those managed surgically with dilatation and curettage (D \& C). A retrospective analysis from 2003-2010 of patients receiving treatment for an EPL. Misoprostol (Cytotec) patients were compared with a randomly selected control group (D \& C). Both the time from the date of treatment to the date at which $\beta$ hCG reached $<5$ $\mathrm{mIU} / \mathrm{mL}$ and the time until a patient resumed FT was evaluated. We compared the rate of retained product of conception (RPOC) between the 2 groups. Statistical analysis of data was conducted by student-t Test and $\chi^{2}$. No statistical significance was observed for resumption of FT between groups. Cytotec group had a greater maintenance of retained products of conception versus D \& C population ( $26 \%$ vs $2 \%$; $p=$ 0.01). More $D \& C$ patients received karyotype results (68\% vs 5\%). A significant difference was not found in resumption time to the next fertility treatment between the medically and surgical treatment. More medically managed patients RPOC requiring D \& C. Although a D \& C is more likely to provide karyotype results, medical management is a viable alternative.
\end{abstract}

Keywords: Misoprostol, Dilatation and Curetta; Fertility Treatment; Cytotec; Retained Products of Conception

\section{INTRODUCTION}

Patients who undergo fertility treatment cope with a challenging process in trying to conceive a healthy off-

"Corresponding author. spring. The emotional and psychological duress is further compounded in cases that result in an early pregnancy loss (EPL). EPL is defined by the sum of both biochemical pregnancy (the loss of concept us after the first measurement of $\beta$ hCG level but before the ultrasound (US) confirmation of implantation) and early clinical miscarriage (the confirmation of a pregnancy loss after US confirmation of a viable pregnancy and before the beginning of the second trimester) [1].

Miscarriage is the most common gynecological emergency (accounting for $75 \%$ of gynecological Emergency Room Visits in the United Kingdom [2]; and two previous studies demonstrated that $15 \%$ of patients who miscarry do so spontaneously in the first trimester $[3,4]$. Approximately one in four women will have an early pregnancy failure during her lifetime [4]. Miscarriages in pregnancies achieved by assisted reproductive technology (ART) procedures may be slightly more frequent than in general population and occur in $16 \%-30 \%$ of patients with confirmed pregnancy [1,5-7]. The major factor affecting this percentage is the mother's age. Women $\leq 35$ years old have a probability rate of $28.5 \%$, compared to $38.6 \%$ in women $\geq 35$ years old $[1,5,7]$. Additional risk factors include smoking and poor quality embryos, which double and triple the risk of a miscarriage respectively [6].

The standard treatment for EPL has been surgical evacuation of the uterus, although in recent years the medical approach (particularly the use of prostaglandins) has become an alternative in patient care. Success in either treatment is defined by abstaining from repeated surgical intervention or surgical treatment for patients who initial used the medical approach within the 30 days after initial treatment [4]. Previous studies have projected the overall expectant management of EPL to have a success rate of $25 \%(4,7)$. Surgically, dilatation and curettage (D \& C) has been a commonly accepted treatment 
for first trimester pregnancy loss; however this procedure contains an inherent risk of complications not to be underestimated. Previous reported complication rates ranged from $5.8 \%$ to $11 \%$ [8,9] with difficulties from pelvic inflammation or the requirement for a secondary D \& $\mathrm{C}$ to evacuate placental and/or fetal tissue remaining in the uterus (termed retained products of conception (RPOC). Other major complications include misdiagnosed ectopic or molar pregnancy cervical tears, uterine perforation, bleeding and a life-threatening hysterectomy $[9,10]$. Asherman's syndrome or intrauterine adhesions (IUA), is a well-known complication following any uterine surgery, such as post-D \& $\mathrm{C}$, and may lead to long-term complications including menstrual aberrations, infertility, recurrent pregnancy loss, and intrauterine growth restriction [11]. The advantages of D \& C include the inherently high procedural success rate of $97 \%$ [4], and the possibility of analyzing the tissue for its chromosomal make-up.

Misoprostol (Cytotec) is a synthetic prostaglandin E1 analogue [12], currently not FDA approved as a single agent protocol for treatment of EPL. Available in oral and intravaginal presentations, the intravaginal route may demonstrate the highest efficacy [13] and the fewest side effects. Misoprostol has the advantage of being inexpensive, easily stored and readily available [10]. There are various dose regimens published in the literature, which report an average efficiency rate of $84 \%$ [4]. The remaining $16 \%$ of patients identified as treatment failures ultimately required a D \& $\mathrm{C}$ to manage RPOC. Complications of treatment with misoprostol occur at a rate of less than 1 in 70 patients [4].

It has been reported that high levels of $\beta \mathrm{hCG}$ (higher than 20,000 IU/1 [7]) as well as previous pregnancies [12], were positively correlated with the need for surgical evacuation [14]. Patient satisfaction is higher in patients treated with misoprostol compared to D \& C [3,12]. Medically treated women experience a few more days of bleeding [7] and pain [2] controlled by either oral or intramuscular analgesia. Although there are clear differences in these managements, neither of the treatment options has been reported to affect future fertility [12].

The loss of a pregnancy leads to a complex psychological event for the mother and the couple; feelings of guilt, anger and sadness may arise. When a spontaneous abortion occurs in a couple who has experienced infertility, the grief may be tempered in some by even the temporary triumph of achieving a new pregnancy [15]. In either case, it has been recommended that following a miscarriage, resources be provided to promote both physical and emotional healing while preparing for the next pregnancy attempt. The best instrument a medical staff has is to help our patients, is to provide sensitive and compassionate care while consulting the treatment options, guiding them to make the right choice in such a crucial moment.

For many patients, a pregnancy loss can ignite a stronger desire to obtain a successful pregnancy. Many infertile couples hope to quickly enroll in a new treatment cycle, thus at times finding it difficult to choose between medical or surgical management. Rapid resumption of treatment may provide an opportunity to reattempt a failed experienced and, as such, could re-establish the feelings of competency and accomplishment associated with a successful birth. Perceived diminished time and personal choice are factors many patients cope with and confine with their health providers in making a choice for management. The best instrument we have as a medical staff to help our patients, is to provide sensitive and compassionate care while consulting the treatment options, guiding them to make the right choice in such a crucial moment. In an effort to better counsel patients that could empower them to make the best decision for their specific case and to establish a "best practice" in the management of EPL in an infertility population, we investigated whether surgical or medical management of an early pregnancy loss led to the more rapid resumption of infertility treatment.

\section{MATERIALS AND METHODS}

We performed a retrospective analysis of our database of 38,385 completed infertility cycles (including natural cycles, stimulated cycles, and Assisted Reproductive Technology cycles), from 2003-2010. There were positive pregnancy tests identified in 7943 cycles and 1533 cycles diagnosed as an EPL. Nineteen patients were identified from our database as having received medical treatment with $800 \mathrm{mg}$ of intravaginal misoprostol for the medical treatment of EPL per office protocol. All remaining RE and IVF losses were alphabetized and assigned a numerical number and using a random number generator a cohort of 44 patients who had EPL surgically managed were selected. Exclusion of either group from the study was based on treatment administered $>2$ weeks after the time of loss.

Post embryo transfer, patient follow up lasted for 9 10 weeks. Beta Human Chorionic Gonadotropin ( $\beta \mathrm{hCG})$ hormone levels and weekly vaginal ultrasounds were used to monitor patient progress. All patients had a least one intrauterine gestational sac and a documented fetal loss prior to patient discharge at nine weeks gestation.

Following fetal loss, the hCG levels were measured weekly until value was $<5 \mathrm{mIU} / \mathrm{mL}$. The duration in time from which the date of intervention to the date at which $\beta \mathrm{hCG}$ reached $<5 \mathrm{mIU} / \mathrm{mL}$ was calculated. Next, we calculated the time until the patient resumed fertility treatment, defined as the $3 \mathrm{rd}$ day of the following menstrual cycle. Finally we compared the rate of known RPOC between the 2 groups and the proportion of patients in 
whom karyotype was able to be obtained on the RPOC. Statistical analysis of data was analyzed by student-t Test and $\chi^{2}$.

\section{RESULTS}

No statistical significance was observed between groups in the number of days to reach a negative $\beta \mathrm{hCG}$ level $(<5$ $\mathrm{mIU} / \mathrm{mL}$ ) following the fetal loss; the mean time in days was $37.2 \pm 16.0$ and $37.7 \pm 15.0$ for the medical and surgical groups respectively (Table 1).

Similar results were observed when measuring the amount of time until the next fertility treatment cycle was initiated. The D \& C group/population observed $54.5 \pm 19.5$ days while the misoprostol group/population observed $60.3 \pm 42.4$ days (Figure 1).

The misoprostol (Cytotec) population had RPOC at a rate of $26 \%$, requiring a subsequent $\mathrm{D} \& \mathrm{C}$; versus the $\mathrm{D}$ \& $\mathrm{C}$ population, which whom RPOC was noted only $2 \%$ of the time (Figure 2). A significant difference was

Table 1. Comparison between the control group (D \& C) and study group (Misoprostol).

\begin{tabular}{cccc}
\hline & $\begin{array}{c}\mathbf{D} \text { \& C } \\
(\mathbf{n}=\mathbf{4 4})\end{array}$ & $\begin{array}{c}\text { Misoprostol } \\
(\mathbf{n}=\mathbf{1 9})\end{array}$ & p value \\
\hline $\begin{array}{c}\text { Time of } \\
\text { Treatment to } \\
\text { Negative } \boldsymbol{\beta} \text { hCG }\end{array}$ & $\begin{array}{c}37.2 \pm 16.0 \\
\text { days }\end{array}$ & $\begin{array}{c}37.7 \pm 15.0 \\
\text { days }\end{array}$ & NS \\
$\begin{array}{c}\text { Time of } \\
\text { Treatment to } \\
\text { Next Cycle }\end{array}$ & $\begin{array}{c}54.5 \pm 19.5 \\
\text { days }\end{array}$ & $\begin{array}{c}60.3 \pm 42.4 \\
\text { days }\end{array}$ & NS \\
$\begin{array}{c}\text { Retained POC } \\
\text { Karyotype } \\
\text { Obtained }\end{array}$ & $2 \%$ & $26 \%$ & $\mathrm{p}=0.01$ \\
\hline
\end{tabular}

Values are mean \pm standard deviation. NS $=$ not statistically significant.

Table 2. Retain Products of Conception (RPOC) between the control group (D \& C) and study group (Misoprostol).

\begin{tabular}{ccc}
\hline & $\begin{array}{c}\text { Surgical } \\
\text { Treatment }\end{array}$ & $\begin{array}{c}\text { Medical Treatment } \\
\text { (Cytotec, } \\
\text { misoprostol) }\end{array}$ \\
\hline Successful Rate & $97 \%$ & $84 \%$ \\
Complication Rate & $5.8 \%-11 \%$ & $16 \%$ \\
$\begin{array}{c}\text { Most Common } \\
\text { Complications }\end{array}$ & $\begin{array}{c}\text { Pelvic } \\
\text { inflammation, } \\
\text { breeding } \\
\text { Conception (RPOC) } \\
\text { Need Hospitalization }\end{array}$ & $\begin{array}{c}\text { Pain, cramping, } \\
\text { variable onset of } \\
\text { action }\end{array}$ \\
Pain & Yes & $16 \%$ - 50\% \\
Bleeding & Mild & Not Necessary \\
& + & Moderate-severe \\
\hline
\end{tabular}

observed in RPOC between these 2 populations ( $\mathrm{p}=$ 0.01). Sixty-eight percent of the D \& C population received karyotype results, as compared to $5 \%$ of Cytotec population $(\mathrm{p}<0.05)$.

\section{DISCUSSION}

The modern treatment of early pregnancy loss was popularized by Hertig and Levingstone in 1944, when they described surgical evacuation of the uterus as the treatment of choice. No significant further debate or investigation or substantial changes in management occurred for the next 50 years [9]. With the development of synthetic prostaglandins to prevent peptic ulcer disease caused by anti-inflammatory drugs, in the 1970s, several uses have been uncovered in different medical fields. In the field of obstetrics and gynecology, prostaglandins were found to be useful in induction of first trimester abortion, evacuation of the uterus in EPL or missed abortion as well as other indications [12]. There has been an increased utilization of the medical approach more re-

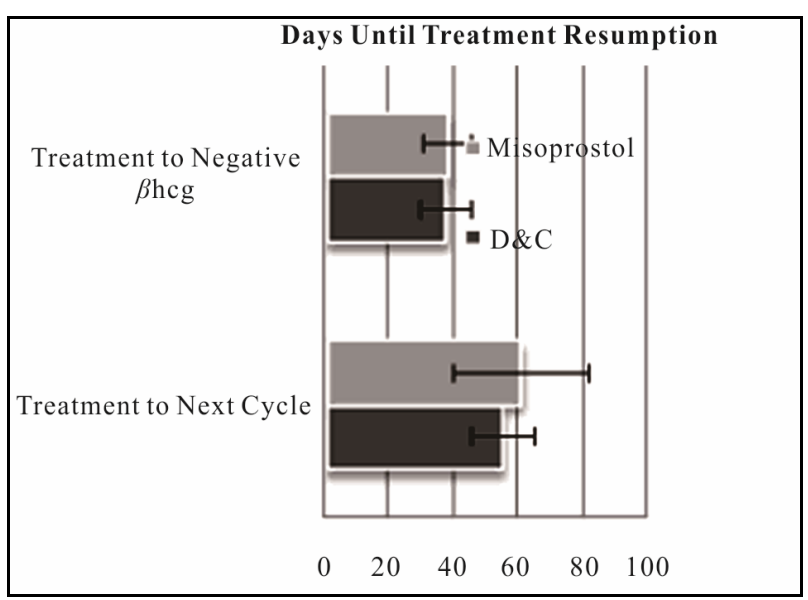

Figure 1. Embryo genotype according to FISH results.

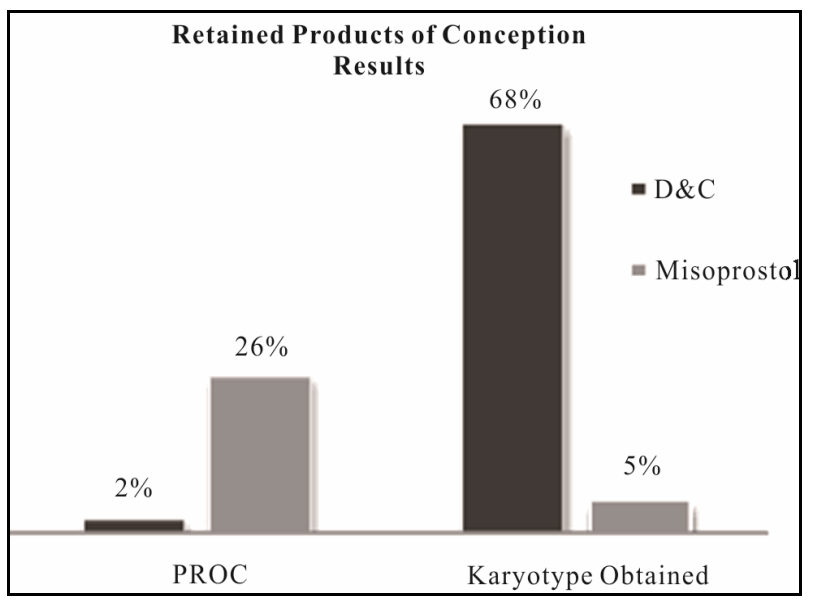

Figure 2. Retained Products of Conception Results. Retained POC: $(\mathrm{p}=0.01)$; Karyotype Obtained: $(\mathrm{p}<0.05)$. 
cently noted and a decreased reliance on surgical treatment with D \& C. This trend led us to our study comparing the advantages and outcomes of medical or surgical management in pregnancy loss, and we thus investigated whether the duration of time to treatment resumption was influenced by treatment choice.

It has been reported, that subfertile couples with long preconception periods have a greater risk for miscarriage (30\% vs 15\%) [16]; taking to account, that maternal age plays the main role, due to the high incidence of aneuploid oocytes (ranging from 36.4\% - 69.23\%) [1,5,7,16, 17]. The age-related effect has been reported, to be caused by the extended duration of time that the oocyte spends arrested in meiosis I, leading to nondisjunction events $[1,17,18]$. Cytogenetic analysis (e.g. karyotype) of RPOC has revealed that a large proportion of these spontaneous miscarriages are a result of chromosomal abnormalities, including autosomal trisomy (68.8\%), polyploidy, chromosome $\times$ monosomy $(2.1 \%)$ and structural rearrangements [17]. In line with other studies, no risk difference of chromosomal abnormalities, between using IVF without ICSI versus IVF with ICSI was noted $[17,18]$.

In our study we found that the mean time to reach a value of $\mathrm{hCG}<5 \mathrm{mIU} / \mathrm{mL}$ for the $\mathrm{D} \& \mathrm{C}$ group was 37.2 \pm 16.0 days versus $37.7 \pm 15.0$ days for misoprostol treatment. This was not statistically significant. While other studies have confirmed procedure success using a follow-up ultrasound to rule out the presence of RPOC or to confirm endometrium thickness $<15 \mathrm{~mm}[2,4,7]$, this was to our knowledge new information and is quite helpful in the counseling of our patients.

The published frequency for RPOC in patients treated with D \& $\mathrm{C}$ varies from $0 \%-4 \%[2,7,12]$ and for misoprostol (Cytotec) is 16\% - 50\% [2,4,7,12] (Table 2) matching our results ( $2 \%$ and $26 \%$ respectively). Differing from KV Chia et al. (2002) [2], who did not find a statistically significant difference between surgical to medical management, our results $(p=0.01)$ found that patients utilizing Cytotec patients were more prone to undergo surgical treatment afterwards. We did not evaluate if a second dose of misoprostol was needed to achieve success.

Nayak et al. (2011) [17] report that only 27\% of their patients underwent successful karyotyping after surgical evacuation of RPOC for an EPL; contrasting with our $68 \%$ result rate. We also encountered that $5 \%$ of the patients medically treated obtained a karyotype.

In conclusion, we did not find a significant difference in time to resumption of fertility treatment between medical and surgical treatment. While medical treatment did not delay the average time, a significant number of medically managed patients suffered from retained tissue and eventually required a D \& C $(26 \%$ p $=0.01)$ (Table

\section{2).}

Providers must give patients information that engenders them to make the best decision after an EPL while remaining non-biased in explaining the benefits and risks associated with both treatments. The provider must remain compassionate to the patient but should avoid swaying or influencing the patient's decision, in the end the patient's decision is their own.

Although medical management of miscarriage is a viable alternative in patients undergoing reproductive treatment, a D \& $\mathrm{C}$ is more likely to provide tissue for karyotyping $(68 \%$ vs $5 \%, \mathrm{p}<0.05)$. Karyotyping is an important contribution to many these patients due to their fertility impairment and may significantly help in their outcome with future ART. To optimally manage patients who have experienced spontaneous abortions, physicians must individualize treatment plans to make the most appropriate decisions. It is important to review program data, understand potential risks and benefits of each option, and to communicate clearly with the patient to choose the best possible treatment option.

\section{REFERENCES}

[1] Dosen, M., Vlaisavljevic, V. and Kovacic, B. (2001) Early miscarriage after single and double blastocyst transfer-An analysis of 1020 blastocyst transfers. Izvirni Clanek, 80, 72-87.

[2] Chia, K.V. and Ogbo, V.I. (2002) Medical termination of missed abortion. Journal of Obstetrics and Gynaecology, 22, 184-186. doi:10.1080/01443610120113382

[3] Demtrouslis, C., Saridogan, E., Kunde, D. and Naftalin, A. (2001) A prospective randomized control trial comparing medical and surgical treatment for early pregnancy failure. Human Reproduction, 16, 365-369.

doi:10.1093/humrep/16.2.365

[4] Zhang, J., Gilles, J.M., Barnhart, K., Creinin, D.M., Westhoff, V. and Fredeerick, M.N. (2005) A comparison of medical management with misoprostol and surgical management for early pregnancy failure. New England Journal of Medicine, 353, 761-769. doi:10.1056/NEJMoa044064

[5] La Sala, G.B., Nucera, G., Galinelli, A., Nicoli, A., Villani, M. and Blickstein, I. (2004) Spontaneous embryonic loss after in vitro fertilization with and without intracytoplasmic sperm injection. Fertility and Sterility, 82, 15361539. doi:10.1016/j.fertnstert.2004.04.062

[6] Winter, E., Wang, J., Davies, M.J. and Norman, R. (2002) Early pregnancy loss following assisted reproductive technology treatment. Human Reproduction, 17, 32203223. doi:10.1093/humrep/17.12.3220

[7] Wang, J.X., Norman, R.J. and Wilcox, A.J. (2004) Incidence of spontaneous abortion among pregnancies produced by assisted reproductive technology. Human Reproduction, 19, 272-277.

[8] Gronlund, A., Gronlund, L., Clevin, L., Andersen, B., 
Palmgren, N. and Lidegaard, O. (2002) Management of missed abortion: Comparison of medical treatment with either mifeprostone misoprostol or misoprostol alone with surgical evacuation. Acta Obstetricia et Gynecologica Scandinavica, 81, 1060-1065.

[9] Chung, T.K.H., Cheung, L.P., Sahota, D.S., Haines, C.J. and Chang, M.Z. (1998) Spontaneous abortion: Shortterm complications following either conservative or surgical management. Australian and New Zealand Journal of Obstetrics and Gynaecology, 38, 61-64. doi:10.1111/j.1479-828X.1998.tb02960.x

[10] Herabutya, Y. and Prasertsawart, P.O. (1997) Misoprostol in the management of missed abortion. International Journal of Gynecology \& Obstetrics, 56, 263-266. doi:10.1016/S0020-7292(96)02815-9

[11] March, C.M. (2011) Management of Asherman's syndrome. Reproductive BioMedicine Online, 23, 63-76. doi:10.1016/j.rbmo.2010.11.018

[12] Stockheim, D. and Carp, H. (2010) Misoprostol for early pregnancy failure. Israel Medical Association Journal, 12, 375-376.

[13] Kulier, R., Gulmezoglu, A.M., Hofmeyr, G.J., Cheng, L.N. and Campana, A. (2004) Medical methods for first tri- mester abortion. Cochrane Database of Systematic Reviews, 1, CD002855.

[14] Odeh, M., Tendler, R., Kais, Mohamed., Maximovsky, O., Ophir, E. and Bornstein, J. (2010) Early pregnancy failure: Factors affecting successful medical treatment. Israel Medical Association Journal, 12, 325-328.

[15] Covington, S. and Burns, L. (2006) Infertility counseling: A comprehensive handbook for clinicians. 2nd Edition, Cambridge University Press, New York.

[16] Brandes, M., Verzijden, J.C.M., Hamilton, C.J.C.M., de Weys, N.P.C., de Bruin, J.P., Bots, R.S.G.M., et al. (2011) Is the fertility treatment itself a risk factor for early pregnancy loss? Reproductive BioMEdicine Online, 22, 192199. doi:10.1016/j.rbmo.2010.10.013

[17] Nayak, S., Pavone, M.E., Milad, M. and Kazer, R. (2011) Aneuploidy rates in failed pregnancies following assisted reproductive technology. Journal of Women's Health, 20, 1239-1243. doi:10.1089/jwh.2010.2648

[18] Al-Asmar, N., Peinado, V., Vera, M., Remohi, J., Pellicer, A., Simon, C., et al. (2012) Chromosomal abnormalities in embryos from couples with a previous aneuploid miscarriage. Fertility and Sterility, in Press. doi:10.1016/j.fertnstert.2012.03.035 